INEEL/CON-99-00028

PREPRINT

Hydropower Resource Assessment Modeling Results

A. Conner
J. Francfort

July 6, 1999 - July 9, 1999

Waterpower '99

This is a preprint of a paper intended for publication in a journal or proceedings. Since changes may be made before publication, this preprint should not be cited or reproduced without permission of the author.

This document was prepared as a account of work sponsored by an agency of the United States Government. Neither the United States Government nor any agency thereof, or any of their employees, makes any warranty, expressed or implied, or assumes any legal liability or responsibility for any third party's use, or the results of such use, of any information, apparatus, product or process disclosed in this report, or represents that its use by such third party would not infringe privately owned rights. The views expressed in this paper are not necessarily those of the U.S. Government or the sponsoring agency. 


\title{
HYDROPOWER RESOURCE ASSESSMENT MODELING RESULTS
}

\author{
By Alison M. Conner and James E. Francfort ${ }^{2}$
}

\section{Abstract}

The U.S. Department of Energy's Hydropower Program developed the Hydropower Evaluation Software to model the undeveloped hydropower resources in the United States based on environmental, legal, and institutional constraints. This Hydropower Resource Assessment effort has identified 5,677 sites that have an undeveloped total capacity of about 30,000 megawatts.

The Idaho National Engineering and Environmental Laboratory developed the Hydropower Evaluation Software with input from the Oak Ridge National Laboratory and several other federal and state agencies. The Hydropower Evaluation Software uses the Federal Energy Regulatory Commission's Hydroelectric Power Resource Assessment database to identify sites with undeveloped hydropower capacity and the estimated megawatts of undeveloped capacity at each site. The Hydropower Evaluation Software integrates this information with environmental values from the National Park Service's National Rivers Inventory database. The database resulting from this modeling project contains environmental attributes for river segments throughout the United States. These environmental attributes include fish, scenery, wildlife, cultural, and recreation values.

Other constraints to development that are modeled include Federal and state legislative protection for river segments that have been identified as being wild and scenic river segments. River segments containing threatened and/or endangered wildlife and fish are also modeled for their influence on hydropower development.

\footnotetext{
${ }^{1}$ Work supported by the U.S. Department of Energy, Assistant Secretary for Energy Efficiency and Renewable Energy (EE), under DOE Idaho Operations Office Contract DE-AC07-94ID13223.

${ }^{2}$ Alison Conner is a Principal Engineer, and Jim Francfort is a Consulting Technical Specialist with Lockheed Martin Idaho Technologies Company, at the Idaho National Engineering and Environmental Laboratory. P.O. Box 1625, Idaho Falls, Idaho, 834153634. (208) 526-7799.
} 
The amount that each attribute affects the likelihood of development is dependent on the prior development of a site. The resource assessment software assumes that a site can have one of three development statuses. The three statuses are (a) completely undeveloped with no type of impoundment or diversion structure present, ( b) developed site without power - some type of civil structure such as a dam, weir, or abandoned power plant may be present but there is no power being generated, or (c) ongoing power generation with additional undeveloped hydropower capacity.

Various state agencies, such as Departments of Water Quality, Environmental Quality, and Fish and Game have also provided input and review to the modeling process. The Association of Dam Safety Officials has served as an advisor to identify the appropriate state agencies from each respective state to assist in the modeling effort. This state input and review has included identifying duplicate sites, missing sites, erroneous information, and additional information describing both the environmental and physical attributes a site possesses.

\section{Introduction}

In 1989, the U.S. Department of Energy, in support of the National Energy Strategy, initiated a multi-agency effort to identify the energy resources available to support the expanding energy demand in the United States, and established the interagency Hydropower Resource Assessment Team to determine the undeveloped hydropower capacity. In connection with these efforts, the Idaho National Engineering and Environmental Laboratory (INEEL) developed the Hydropower Evaluation Software (HES) to model the undeveloped hydropower resources in the United States based on environmental, legal, and institutional constraints. This Hydropower Resource Assessment effort has identified 5,677 sites that have a total undeveloped capacity of about 30,000 megawatts.

\section{HES Goal}

The goal of the HES is to ensure that a set of uniform criteria is used to determine the viable national undeveloped hydropower capacity. Undeveloped hydropower is not limited to that which could be developed at new sites; it also includes the hydropower that could be produced at sites that currently have generating capacity but are not developed to their full potential. The set of uniform criteria includes environmental, legal, and institutional attributes.

The HES was not intended to provide precise development factors for individual sites, but to provide regional or state capacity totals. Because the software was developed as a generic measurement tool encompassing national issues, regional and state totals must be considered judiciously; various local issues may skew hydropower capacity totals. Employing HES as a national measurement tool will smooth any local anomalies. 


\section{Model Development}

The HES was developed by the INEEL, with input from the Oak Ridge National Laboratory and several other federal and state agencies. The Association of Dam Safety Officials served as an advisor to identify the appropriate state agencies from each respective state to assist in the modeling effort. The INEEL also received valuable assistance from the Southwestern Power Administration, which helped define the database requirements and the reporting capabilities required by a power marketing administration. The HES, both a database and a probability-factor computer model, is a menu-driven software application that is intended to be user-friendly. Computer screens and report generation capabilities were developed to meet the needs of users nationwide.

Various state agencies, such as Departments of Water Quality, Environmental Quality, and Fish and Game provided input and review to the modeling process. This state input and review included identifying duplicate sites, missing sites, erroneous information, and additional information describing both the environmental and physical attributes a site possesses.

The HES uses the Federal Energy Regulatory Commission's Hydroelectric Power Resource Assessment database to identify sites with undeveloped hydropower capacity and the estimated megawatts of undeveloped capacity at each site. The HES integrates this information with environmental values from the National Park Service's National Rivers Inventory database. The database resulting from this modeling project contains environmental attributes for river segments throughout the United States.

\section{Suitability Factor Values}

HES uses environmental attribute data to generate an overall project suitability factor between 0.1 and 0.9 , with 0.1 representing the lowest possibility of development and 0.9 representing the least impediment to development (see Table 1 for potential values). Suitability factors reflect the probability that environmental considerations can make a project site unacceptable, prohibiting its development. A combination of attributes results in a lower suitability factor because multiple environmental considerations reduce the likelihood that a site may be developed to its full capacity.

The suitability factors were developed in conjunction with Oak Ridge National Laboratory staff experienced in hydropower licensing cases. These suitability factors are appropriate only for the regional analysis of overall hydropower development capacity and are not useful for determining the ultimate viability of developing a specific project site. 
Table 1. Valuation of environmental attributes.

\begin{tabular}{ll} 
Effect of environmental attribute & Value of suitability factor \\
\hline Least impediment to development & 0.90 \\
Minor reduction in likelihood of development & 0.75 \\
Likelihood of development reduced by half & 0.50 \\
Major reduction in likelihood of development & 0.25 \\
Development prohibited or highly unlikely & 0.10 \\
\hline
\end{tabular}

The amount that each attribute affects the likelihood of development depends on the physical status of a site. The resources assessment software assumes that a site can have one of three development statuses:

$\mathrm{W}=$ Developed hydropower site with power.

$\mathrm{W} / \mathrm{O}=$ Developed site without power generation (the site has some type of developed impoundment or diversion structure).

$\mathrm{U}=$ Undeveloped site (the site does not have power generation capability, no developed impoundment, nor a diversion structure).

Other HES-modeled constraints include Federal, state, and regulatory protection for river segments that have been identified as being wild and scenic. River segments containing threatened and/or endangered wildlife and fish are also modeled for their influence on hydropower development.

\section{Summary of Model Results}

Figures 1 and 2 summarize the number of potential hydropower sites in each of the 50 states. The number of sites does not change after the HES adjustments are made. California has the highest number of sites (763) and the most undeveloped sites (463), and Delaware has the fewest sites (1). Wisconsin has the largest number of developed sites (46) that also have additional undeveloped hydropower capacity. Delaware, Florida, Louisiana, Mississippi, New Hampshire, New Jersey, Rhode Island, Tennessee, West Virginia, and Wyoming do not have any sites with power that are not already developed to their full potential capacity. The total number of sites for the 50 states is 5,677. Developed sites with existing power (389) account for about $7 \%$ of the total, while there are 2,527 developed sites without power, and 2,761 undeveloped sites. 


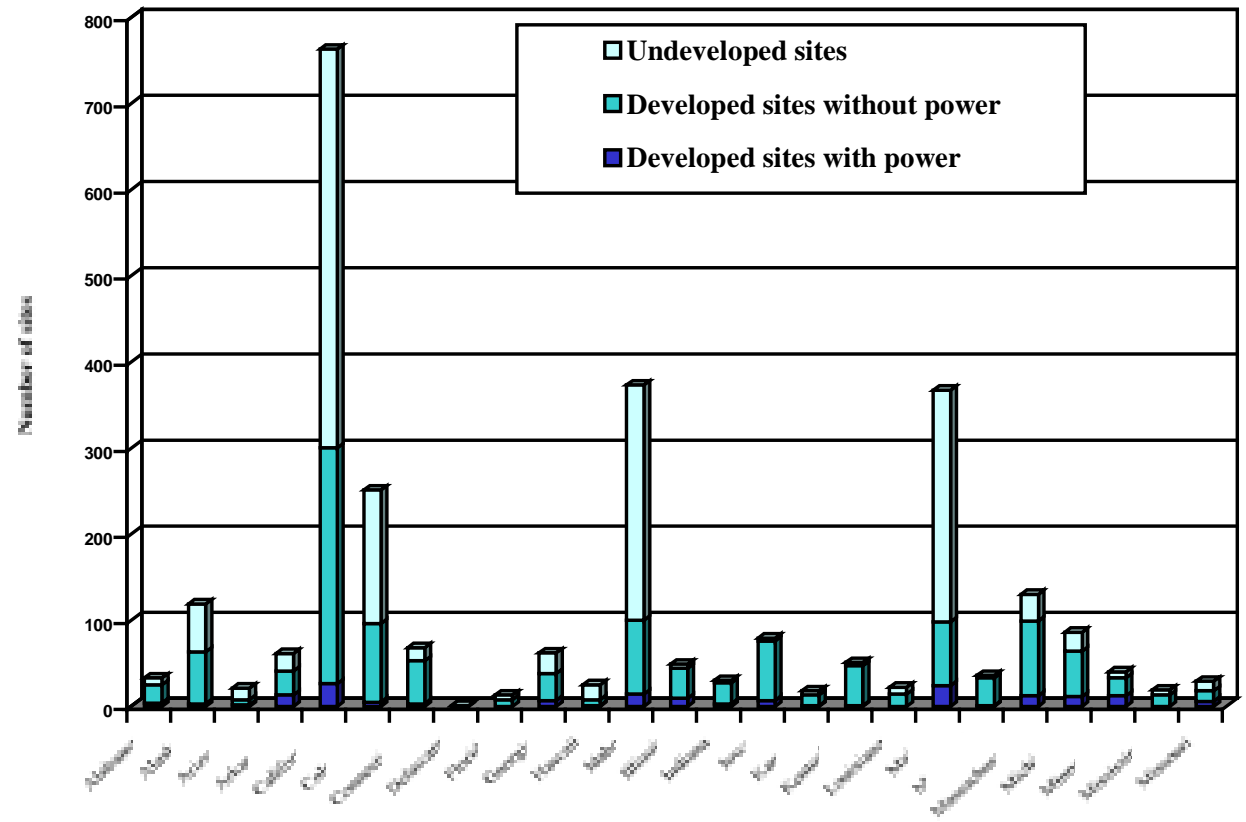

Figure 1. Number of sites with undeveloped hydropower capacity by state, for Alabama through Missouri.

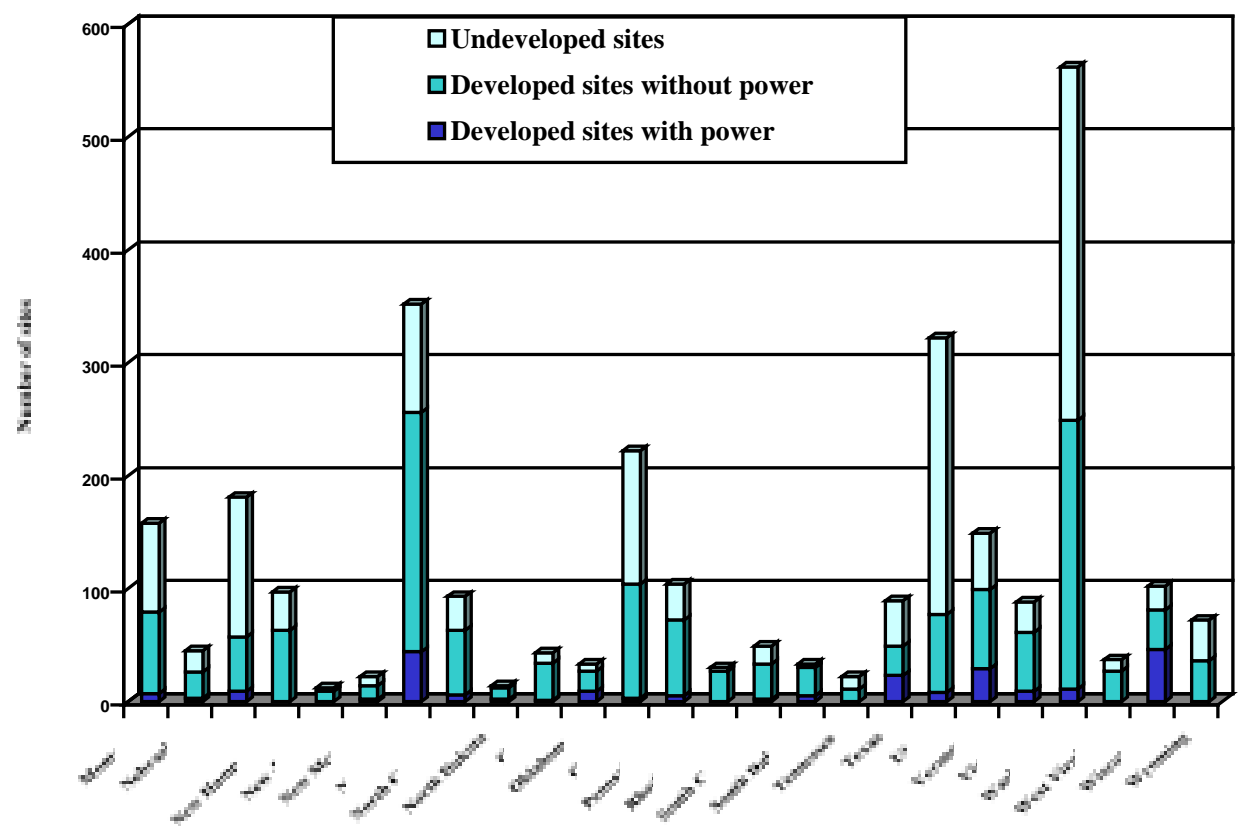

Figure 2. Number of sites with undeveloped hydropower capacity by state, for Montana through Wyoming. 
Figures 3 and 4 summarize the nonmodeled (unadjusted) and the HES modeled (adjusted) total undeveloped hydropower capacity. Washington has the largest undeveloped capacity after adjustment for environmental attributes using the HES. Delaware remains the state with the least undeveloped capacity with or without modeling. The unadjusted undeveloped hydropower capacity total for the 50 states is $69,897 \mathrm{MW}$. HES lowers this estimate about $57 \%$ to $29,780 \mathrm{MW}$.

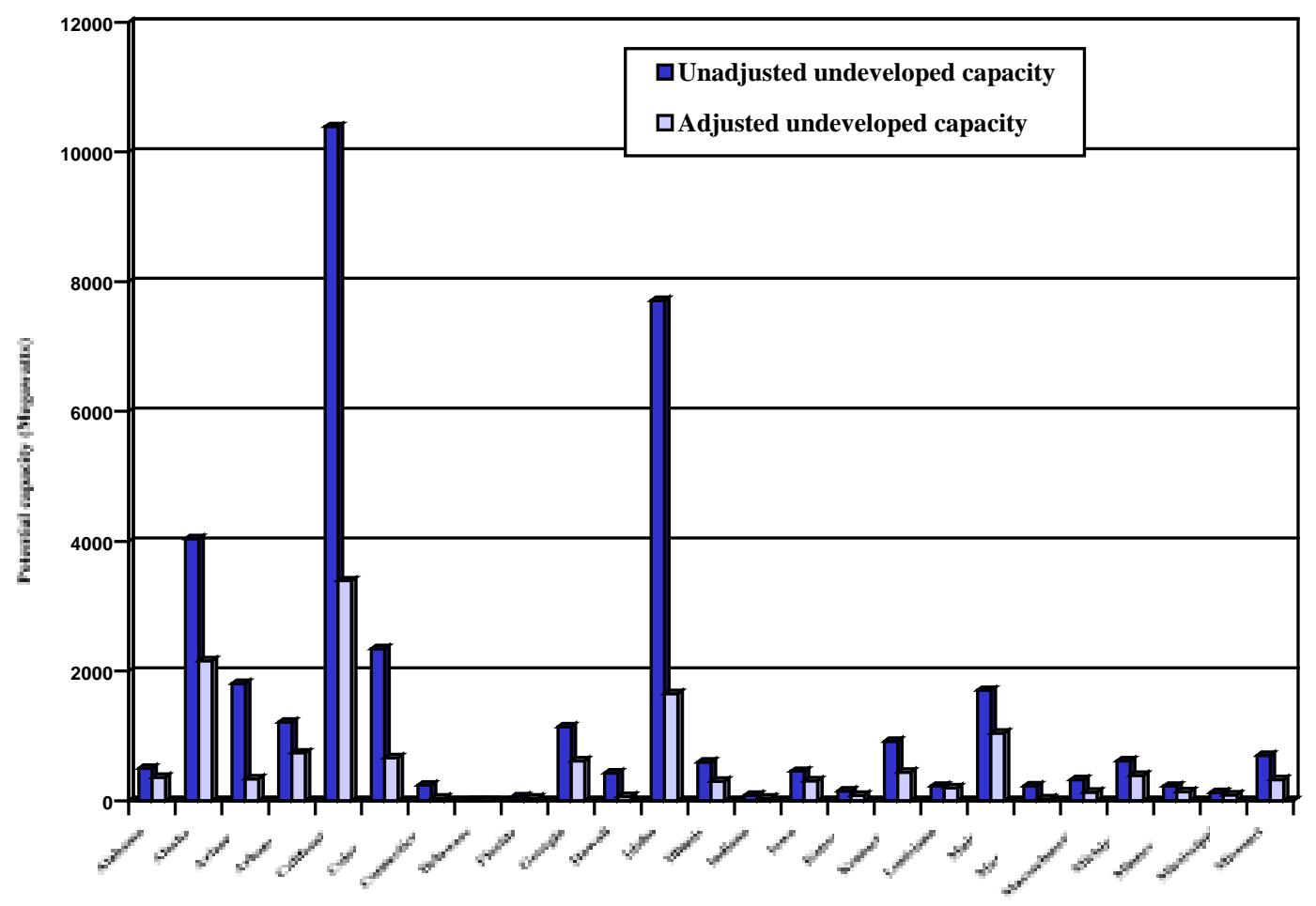

Figure 3. Total undeveloped hydropower capacity by state for Alabama through Missouri. 


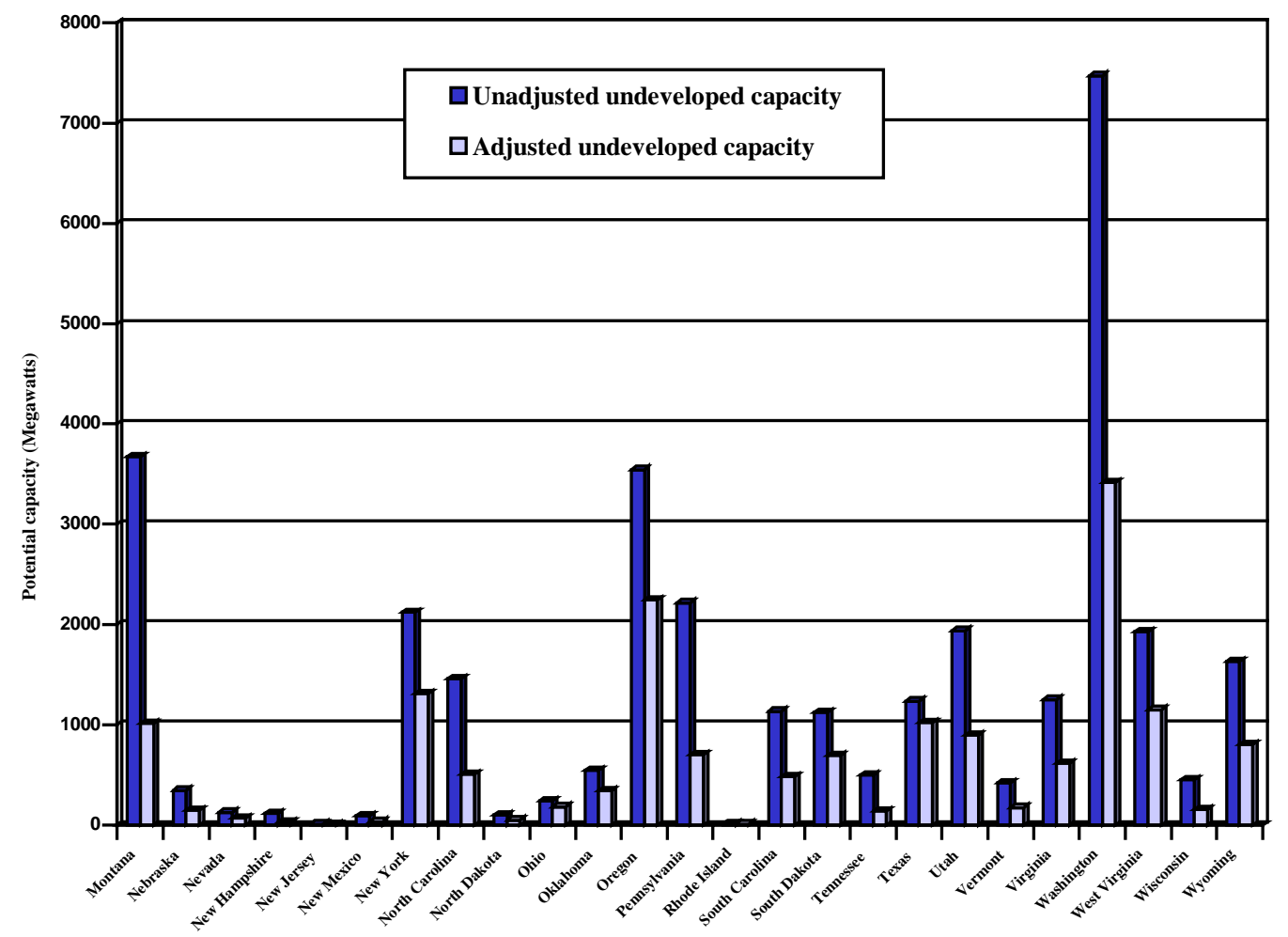

Figure 4. Total undeveloped hydropower capacity by state for Montana through Wyoming.

Figure 5 compares unadjusted and adjusted total undeveloped hydropower capacity by site status. As expected by the probability-weighing scheme, the capacity associated with undeveloped sites has the largest (74\%) reduction from 32,452 to $8,466 \mathrm{MW}$, or a loss of 23,986 MW. Developed sites with power (389) have a $45 \%$ reduction in undeveloped capacity from 7,820 MW to 4,316 MW, or a loss of 3,504 MW. Developed sites without power $(2,527)$ have a $43 \%$ reduction from 29,625 MW to 16,998 MW, or a loss of 12,627 MW. Developed sites without power have the greatest overall capacity after adjustment (16,998 MW). The additional hydropower capacity for developed sites with current power generation remains considerably less (4,316 MW). 


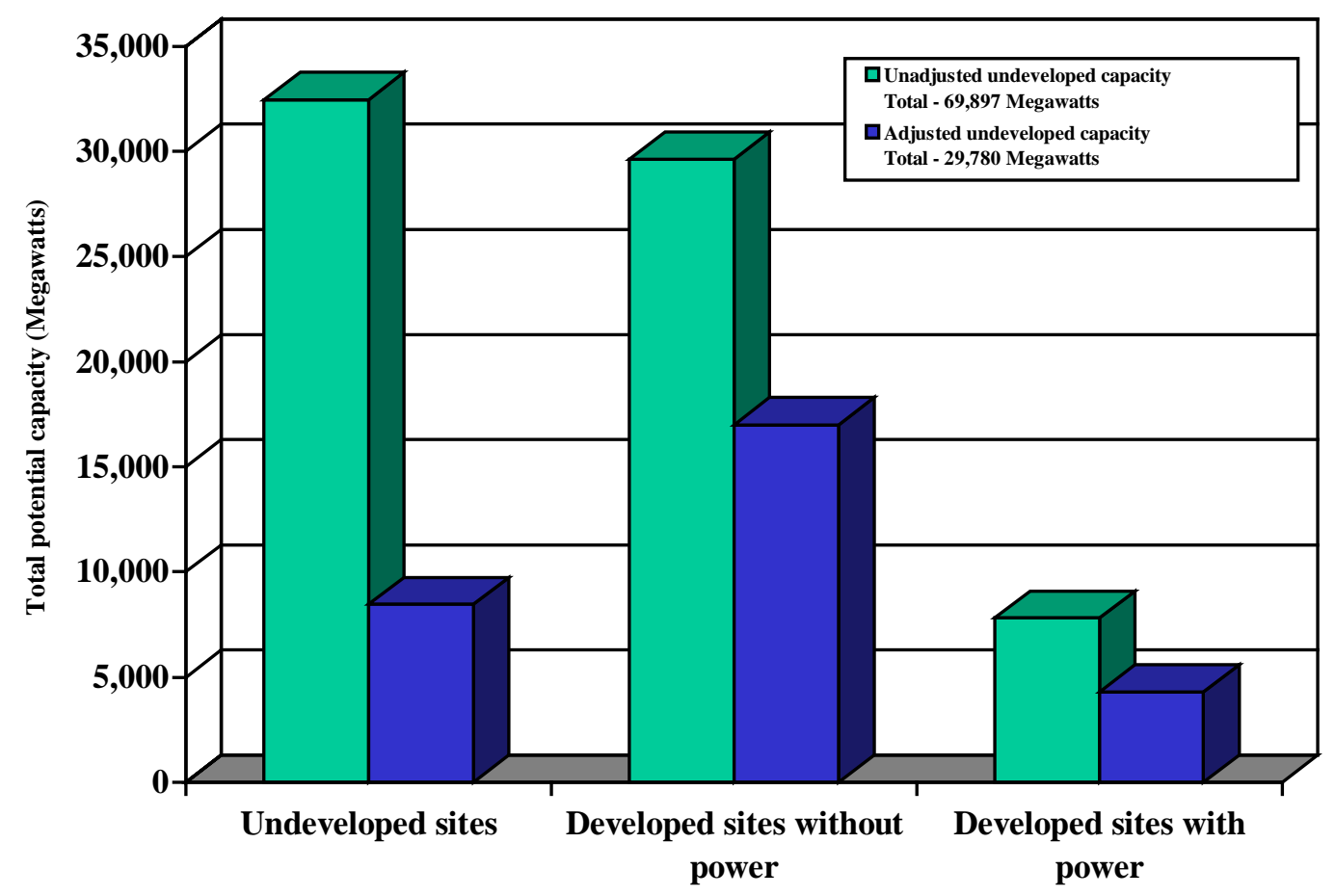

Figure 5. Total undeveloped hydropower capacity by site status.

As shown in Figure 6, the majority of the hydropower sites (53\% or 2,990) are located within seven states, California, Colorado, Idaho, Maine, New York, Utah, and Washington, and five of those are in the western United States. 


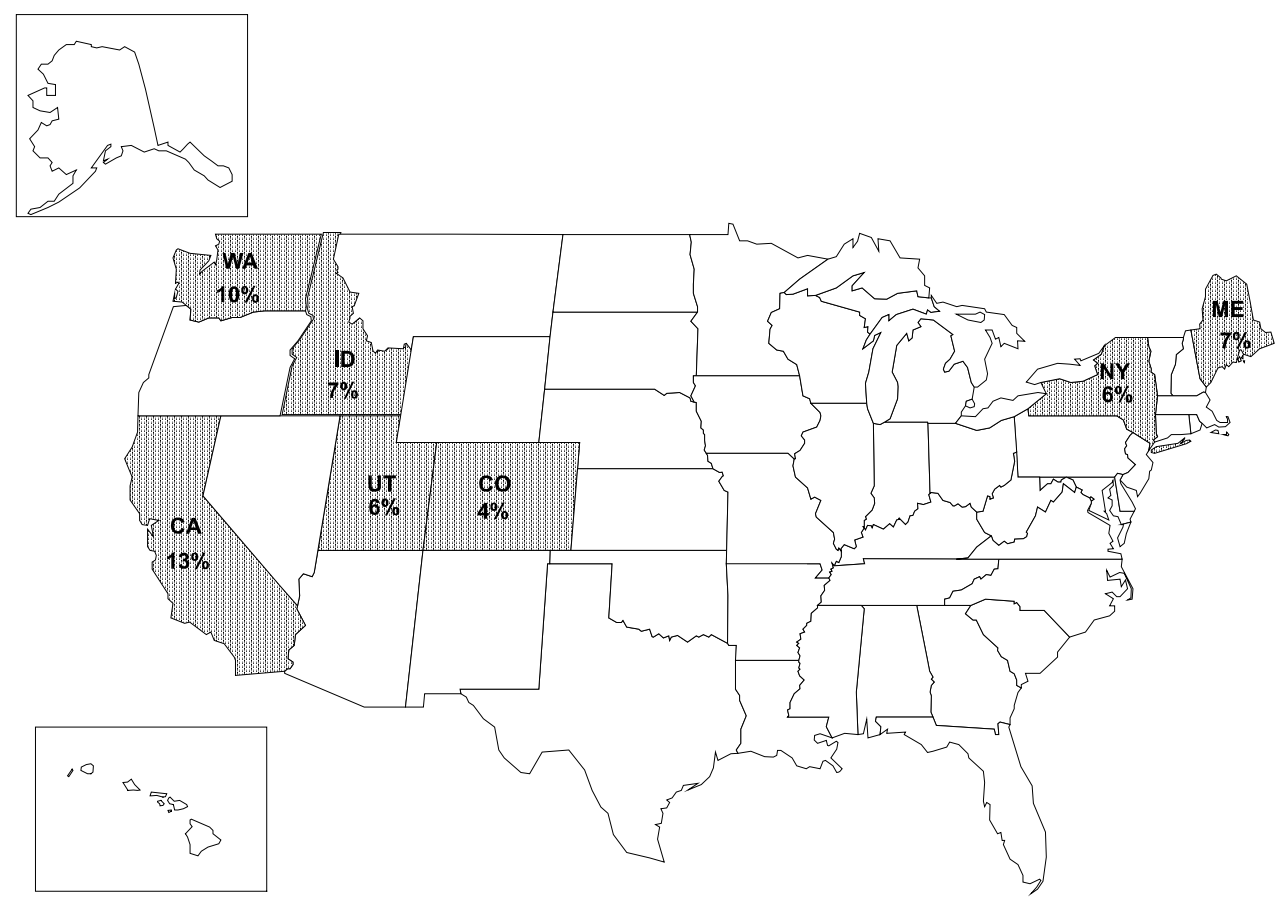

Figure 6. Location of the majority of hydropower sites by state, reported as a percentage of the total number of sites.

\section{Summary}

There will always be a decrease in undeveloped hydropower capacity when environmental, legal, and institutional attributes are factored into the suitability for development. After loading hydropower data for 50 states into the HES and checking the data with the respective states, the analysis indicates that undeveloped hydropower capacity will drop by about $43 \%$. The greatest decrease for any state is always at undeveloped sites.

HES results are obtained in a viable, low-cost manner and can be used by developers as a preliminary means for identifying developable sites. These results provide a peerless means for identifying the undeveloped hydropower capacity that is essential for ensuring continued energy growth, which is necessary for the continued economic strength of the United States. 
Application of HES to current data significantly reduces state and regional totals for undeveloped hydropower capacity. However, an abundance of potential sites remain that are likely to be developed, given the current environmental awareness and geopolitical constraints. Strategies may need to be formulated to further assess those sites with the most potential for development.

\section{Obtaining Individual State Data}

The Hydropower Evaluation Software results for the 50 states and additional information on the HES can be obtained by accessing the U.S. Department of Energy's Hydropower Program homepage on the Internet at "www.inel.gov/national/hydropower/index.html". 